\title{
SEDIMENTOLOGIA, ESTRATIGRAFIA E EXPLOTAÇÃO DE HIDROCARBONETOS: ALGUNS CONCEITOS E TENDÊNCIAS
}

\author{
W.L.Lanzarini ${ }^{1}$ \\ G.Amara/2
}

A atividade da área de geologia econômica comumente conhecida como geologia do petróleo é subdividida em geologia de exploração, e geologia de explotação ou de desenvolvimento, ou ainda, de reservatório de hidrocarboneto (petróleo e gás natural). A atividade exploratória compreende desde os mapeamentos regionais, os levantamentos geofísicos principalmente através do método da sísmica de reflexão, a avaliação do potencial geoquímico, e a perfuração de poços estratigráficos e pioneiros, até a descoberta de um ou mais campos com potencial econômico.

A geologia de explotação começa a partir da preocupação em "desenvolver" o campo, isto é, produzir hidrocarboneto de forma otimizada. Então, uma das principais atividades do geólogo é o estudo da geometria e heterogeneidades da "zona" produtora, na grande maioria depósitos de rochas sedimentares siliciclásticas e carbonáticas com porosidade saturada de hidrocarboneto e permeabilidade favorável ao fluxo fluido.

O Brasil possui mais de 600 campos já descobertos, desde campos com mais de 20 a 30 anos de produção de poucas dezenas de barris/dia, até campos descobertos mais recentemente, de grande porte e produções de dezenas de milhares de barris/dia. Nossos principais resenvatórios são arenitos e conglomerados turbidfticos do Cretáceo e Terciário da Bacia de Campos, calcarenitos e calcirruditos oolfticos/oncolfticos de barras de plataforma da Formação Macaé, do Albiano, também na Bacia de Campos, e arenitos fluviais, fluvio-eólicos e fluvio-transicionais das Bacias

\footnotetext{
1Pós-graduação, Departamento de Paleontologia e Estratigrafia, Instituto de Geociências, USP e Cenpes.

2Departamento de Paleontologia e Estratigrafia, Instituto de Geociências, USP.
} 
do Recôncavo, Potiguar e Sergipe-Alagoas, dentre outras. Todos estes reservatórios exigem estudos detalhados e contínuos de petrologia sedimentar, até a exaustão ou o limite de produção econômica, o qual pode estar sendo continuamente modificado pela implantação de métodos de recuperação secundária ou terciária, ou pela flutuação do preço do óleo.

A geometria dos reservatórios pode ser subdividida em geometria externa e interna. No estudo da primeira encontra-se a aplicação da análise faciológia, a identificação de ambientes deposicionais, o mapeamento tridimensional de fácies e subfácies através da confecção de mapas paleogeográficos e seções estratigráficas e ou estruturais. No estudo da geometria interna, em escala microscópica, tem-se a aplicação da petrografia sedimentar, a identificação dos constituintes do arcabouço, matriz e cimento, texturas, processos diagenéticos e, tipos e distribuição da porosidade.

Algumas tendências em sedimentologia $\theta$ estratigrafia aplicada ao estudo de reservatórios são: (a) a utilização da bioestratigrafia e da estratigrafia de seqüências em pequenos intervalos estratigráficos, assim como da geofísica de reservatórios, principalmente a sísmica 3D, de alta resolução, como ferramentas para a descrição detalhada da geometria dos depósitos; (b) a aplicação de técnicas geomatemáticas e da geoestatística ao estudo da distribuição de parâmetros faciológicos, petrográficos, petrofísicos e de produção dos reservatórios, predominantemente técnicas de simulação matemática determinística ou probabilística. (c) a aplicação do processamento digital ao estudo de imagens de rochas, em afloramentos, testemunhos e seção delgada; e (d), como suporte, o crescente uso de equipamentos e programas de computação que viabilizam o tratamento integrado dos dados, assim como resultados a tempo de serem incorporados ao processo explotatório. 